\title{
Subcutaneous Phaeohyphomycosis Due to Pyrenochaeta romeroi Mimicking a Synovial Cyst
}

\author{
Aurélien Dinh ${ }^{1 *}$, Bruno Levy2 Frédérique Bouchand $^{3}$, Benjamin Davido', Clara Duran ${ }^{1}$, \\ Marin Cristi ${ }^{4}$, Adrien Felter ${ }^{5}$, Jérôme Salomon ${ }^{1,6}$ and Nawel Ait Ammar ${ }^{7}$ \\ ${ }^{1}$ Infectious Diseases Unit, Raymond Poincaré University Hospital, Garches, France, ${ }^{2}$ Orthopaedic Surgery Unit, Ambroise \\ Paré University Hospital, Boulogne-Billancourt, France, ${ }^{3}$ Pharmacy Department, Raymond Poincaré University Hospital, \\ Garches, France, ${ }^{4}$ Pathology Unit, Ambroise Paré University Hospital, Boulogne-Billancourt, France, ${ }^{5}$ Radiology \\ Department, Raymond Poincaré University Hospital, Garches, France, ${ }^{6}$ Institut Pasteur, Inserm UMR 1181, Paris, France, \\ ${ }^{7}$ Mycology and Parasitology Unit, Henri Mondor Hospital, Créteil, France
}

\section{OPEN ACCESS}

Edited by: Leonard Peruski,

US Centers for Disease Control and Prevention, USA

Reviewed by:

Haider Abdul-Lateef Mousa,

University of Basrah, Iraq

Celio Geraldo Freire De Lima,

Federal University of Rio de Janeiro,

Brazil

${ }^{*}$ Correspondence: Aurélien Dinh aurelien.dinh@aphp.fr

Specialty section:

This article was submitted to Infectious Diseases,

a section of the journal Frontiers in Microbiology

Received: 17 June 2016 Accepted: 24 August 2016 Published: 31 August 2016

Citation:

Dinh A, Levy B, Bouchand $F$

Davido B, Duran C, Cristi M,

Felter A, Salomon $J$ and Ait Ammar N (2016) Subcutaneous

Phaeohyphomycosis Due to Pyrenochaeta romeroi Mimicking a Synovial Cyst.

Front. Microbiol. 7:1405. doi: 10.3389/fmicb.2016.01405
Opportunistic subcutaneous fungal infections are increasing nowadays due to the growing number of medical conditions causing immunosuppression, especially organ transplant. The incidence rate of subcutaneous phaeohyphomycosis is very low. Most studies found are case reports. They showed a wide variation of clinical presentations. Pyrenochaeta romeroi, a fungus from the Dematiaceae group is a saprophyte found in soil and plants and a possible causative agent of phaeohyphomycosis. We present a rare case of subcutaneous phaeohyphomycosis caused by $P$. romeroi mimicking a synovial cyst in a diabetic patient.

Keywords: Pyrenochaeta, phaeohyphomycosis, fungal infection, surgical treatment, immunosuppression

\section{INTRODUCTION}

Phaeohyphomycosis is a heterogeneous group of infections due to dematiaceous fungi with several clinical presentations, from superficial to deep infections (Borelli, 1979; Rinaldi, 1996). Subcutaneous phaeohyphomycosis cases are rare and clinical manifestations may vary (Vásquezdel-Mercado et al., 2013). One study found that the incidence rate of phaeohyphomycosis in a tertiary care center hospital varies from 1.0 to 3.1 cases per 100,000 patient-days (Ben-Ami et al., 2009). They affect predominantly the skin and can disseminate in immunocompromised patients, especially transplant patients.

There are more than 100 species of dematiaceous fungi associated with phaeohyphomycosis (Alternaria spp., Curvularia spp., and Exophiala spp...). There is no known correlation between etiologic agents and the clinical presentation of phaeohyphomycosis (Oliveira et al., 2016).

Pyrenochaeta romeroi has been recently described as a causative agent of phaeohyphomycotic cyst in few cases while it was already known as an agent of mycetoma (Thammayya et al., 1979; Girard et al., 2004; Badali et al., 2010a; Khan et al., 2011). This saprophytic fungus is widely distributed in the environment and found in soil, wood and plants in tropical area. It was first described by Borelli (1979).

The diagnosis of subcutaneous phaeohyphomycosis is difficult because of the lesions' clinical polymorphism. It is usually established with histological examination and culture.

We present a case of subcutaneous phaeohyphomycosis due to $P$. romeroi mimicking a synovial cyst in a diabetic patient's foot. 


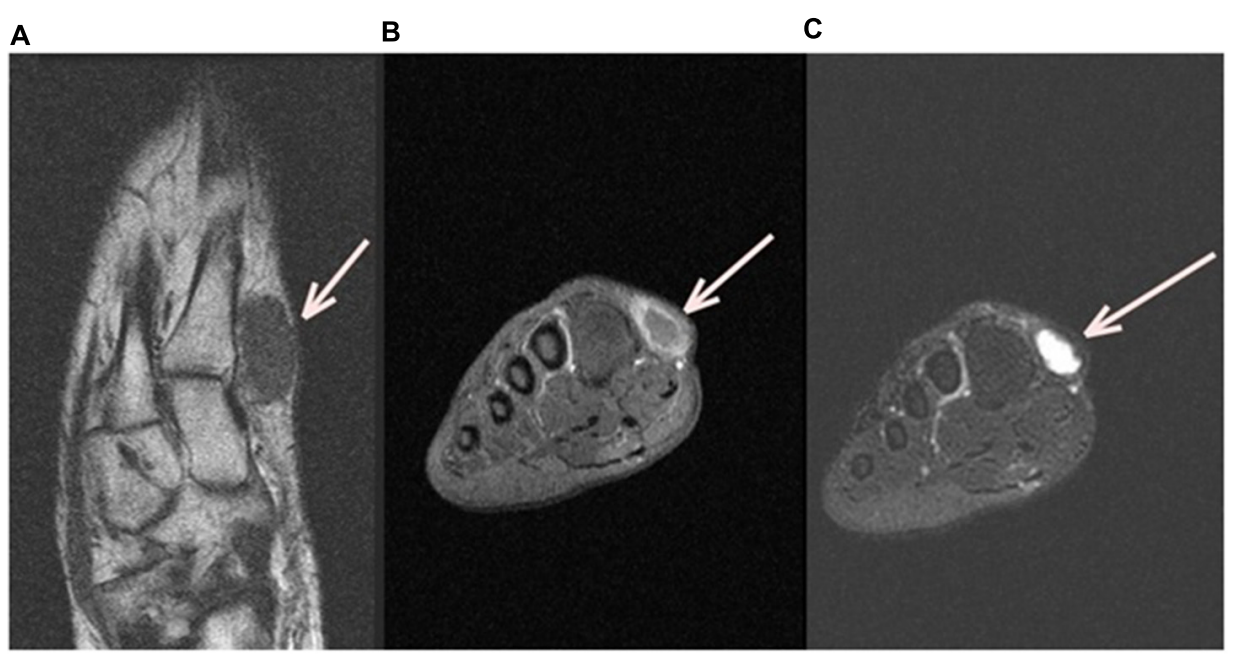

FIGURE 1 | Left Foot MRI (Magnetic Resonance Image). Axial MRI T1 left foot image (A) shows a subcutaneous ovoid mass of $3 \mathrm{~cm} \times 2 \mathrm{~cm}$ in contact with the first metatarse (white arrow), coronal T1 fat sat with gadolinium (B) and Coronal T2 fat sat (C) show, respectively, an hyposignal T1 and a hyper signal T2 with peripheric enhancement after injection.

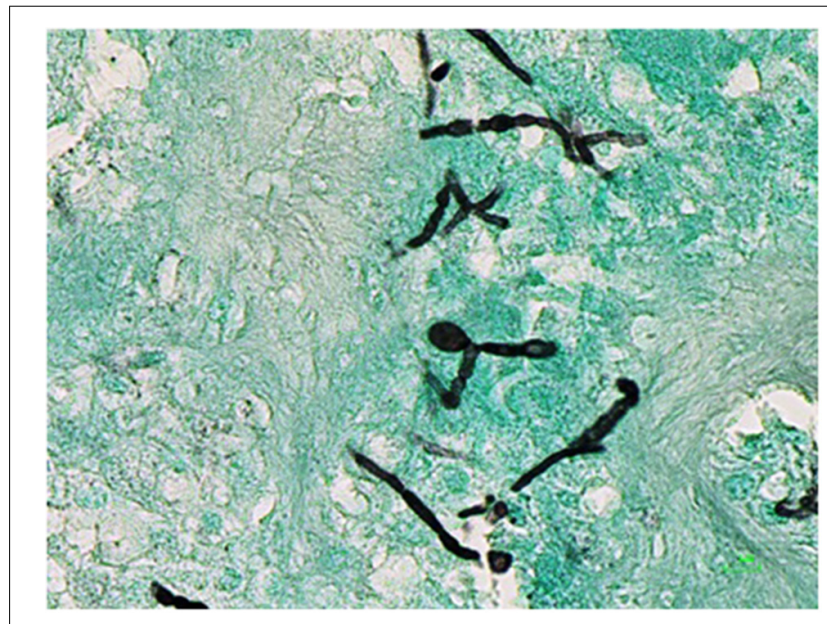

FIGURE 2 | Histological examination of the cyst on Grocott staining.

\section{CASE REPORT}

In April 2014, a 47-year-old woman, with a 2-year painful swelling on the inner edge of her right foot, was admitted to our hospital. She had no relevant medical history, except diabetes mellitus diagnosed 3 years before. She was born in Benin and had lived in France for 19 years. She was unemployed. Her last trip to Benin was 4 years ago and she stayed for a month. No notion of trauma was found.

Local examination revealed a soft to firm mass at the first radius of the right foot. It was slightly mobile, tender with normal overlying skin, and painful to pressure. The rest of clinical examination was normal. Biological investigations including hemogram, chemistry panel, C Reactive Protein level, liver enzyme level, serum protein electrophoresis, and serum

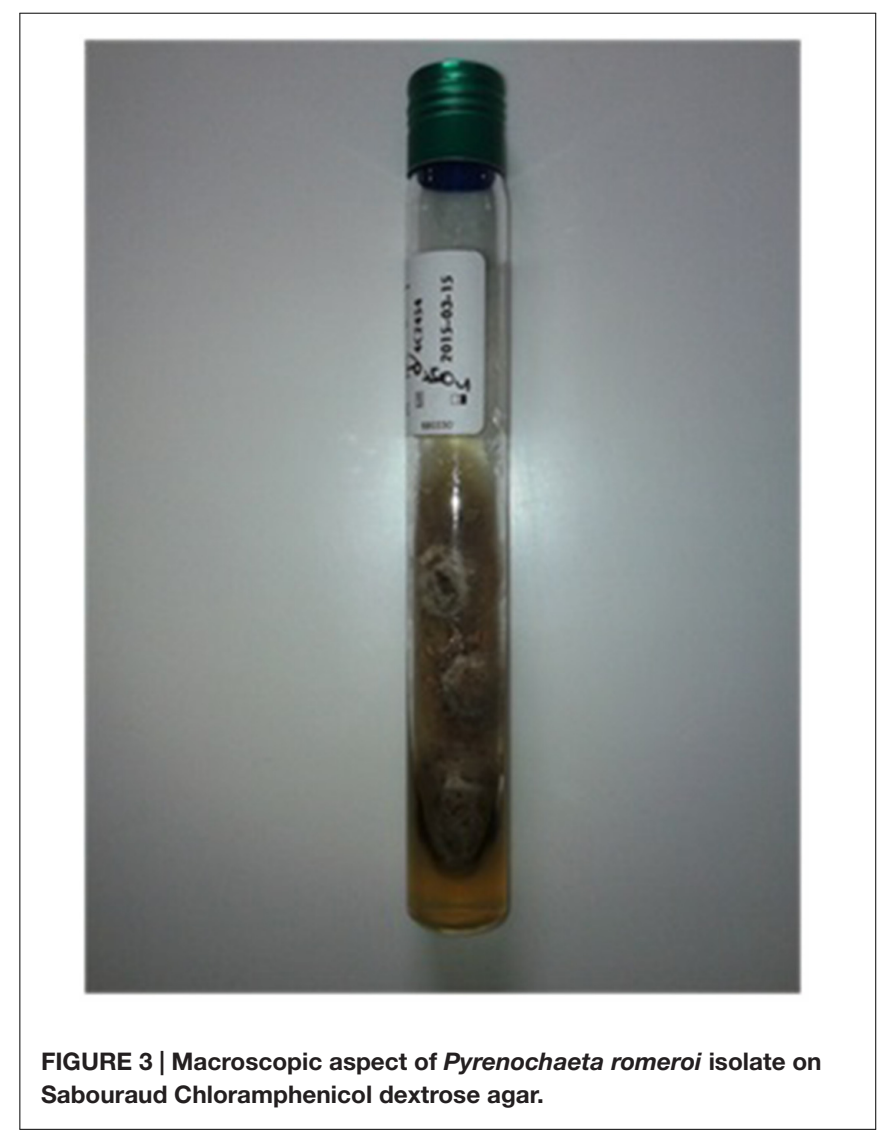

immunoglobulin electrophoresis were all normal, except for blood glucose (413 g/dL). HIV serology was negative.

A foot MRI (Magnetic Resonance Image) was realized. It showed a subcutaneous ovoid mass of $3 \mathrm{~cm} \times 2 \mathrm{~cm}$ in contact with 


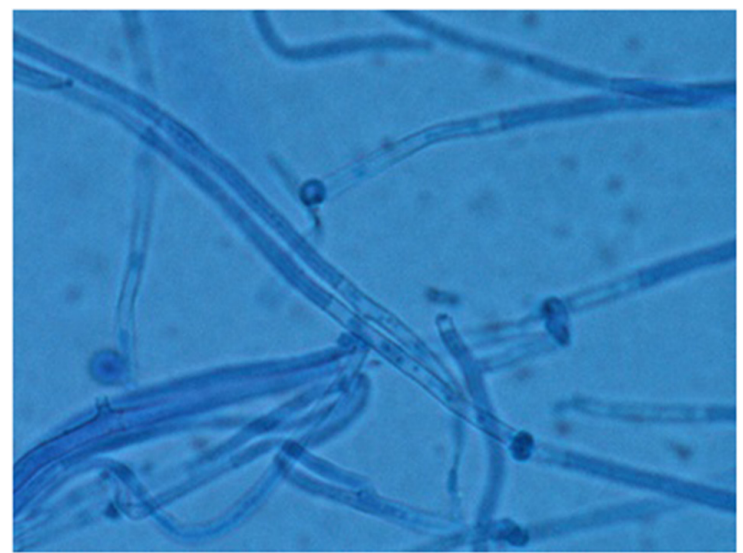

FIGURE 4 | Microscopic aspect of $P$. romeroi isolate (Blue cotton, $\times 40$ ).

the first metatarse, associated to hyposignal T1 and hypersignal T2 with peripheric enhancement after injection (Figure 1), suggesting a diagnosis of synovial cyst.

A surgical treatment was performed. The cyst was incised and drained. As the patient presented no symptom, she had no antimicrobial prescription other than Amoxicillin clavulanate during 48 h. Patient was discharged 2 days after intervention without complications.

The cyst was sent for histological and microbiological analysis. Histology revealed a dense fibrous tissue associated with a granulomatous inflammation with abundant giant cells and a necrosis in which were found many irregular septate hyphae (Figure 2). Routine bacteriological cultures were negative. A dematiaceous mold grew in 10 days on Löwenstein-Jensen medium. A subculture on Sabouraud dextrose agar with Chloramphenicol was performed and incubated at $30^{\circ} \mathrm{C}$. The macroscopic aspect of the culture was velvety and grayish (Figure 3). The microscopic aspect revealed septate and branched hyphae (Figure 4). No conidia were observed. On the basis of these microscopic and macroscopic examinations, the isolate was not identified.

Molecular identification was performed by PCR amplification and sequencing of internal transcribed spacer (ITS) regions. A homology for the obtained sequences was carried out using NCBI BLAST. The clinical isolate was identified as $P$. romeroi.

Antifungal MIC could not be determined due to the lack of growth on RPMI media.

Since the cyst's surgical ablation was complete, no antifungal prescription was needed and the 2-year follow up did not show any relapse.

\section{DISCUSSION}

Subcutaneous phaeohyphomycosis often affect patients in immunosuppressive conditions, particularly kidney transplant and rheumatoid arthritis (Ronan et al., 1993). Its clinical spectrum is wide from local to systemic dissemination. P. romeroi is a saprophyte mostly found in soil or associated with plants, usually encountered in tropical and subtropical areas (Badali et al., 2010a; Khan et al., 2011). Agricultural workers have an increased risk of acquiring infection (Khan et al., 2011). In our case, the patient is a housewife but used to go in fields in Benin 4 years ago. The fungus is generally inoculated through direct traumatism by a plant or a soiled object. Though no history of trauma was found with our patient, foot localization might suggest this point of entrance for the fungus. Subcutaneous infections due to $P$. romeroi are rare (Girard et al., 2004; Badali et al., 2010a; Khan et al., 2011; Oliveira et al., 2016; Sharma et al., 2016). Cases are mostly related to immunosuppressive conditions (renal transplant, rheumatoid arthritis, corticosteroid...). Our patient only had diabetes mellitus. To our knowledge, this is the second case of subcutaneous phaeohyphomycosis due to $P$. romeroi described in a diabetic patient (Yadav et al., 2015).

The identification of Pyrenochaeta species is difficult (Badali et al., 2010a; Khan et al., 2011). Often pycnidia are not produced until 3 weeks on specific media. Thus, molecular identification is needed, using ITS sequencing as recommended by Santos et al. (2013). Based on a recent phylogenetic study, de Gruyter et al. (2009) renamed this fungus as Medicopsis romeroi.

No standard therapy is available for this infection. However, literature shows that surgery treatment has been successfully applied in some cases (Girard et al., 2004; Ferrer et al., 2009; Badali et al., 2010b; Verkley et al., 2010; Khan et al., 2011). The literature also suggests that antifungal susceptibility of Pyrenochaeta species is poorly documented due to low availability and low number of clinical isolates. Recently, ESCMID issued recommendations for treatment of phaeohyphomycosis. Surgery is the recommended first-line treatment, in addition to itraconazole or voriconazole to prevent any dissemination in immunocompromised patients (Chowdhary et al., 2014). Our patient showed signs of improvement after surgical treatment without any antifungal treatment.

\section{CONCLUDING REMARKS}

We report an atypical case of subcutaneous phaeohyphomycosis due to $P$. romeroi mimicking a synovial cyst. This atypical presentation occurred in a non-immunosuppressed diabetic patient and healed without specific antimicrobial treatment. This presentation has not been reported before to the best of our knowledge.

\section{ETHICS STATEMENT}

The patient signed a written consent form.

\section{AUTHOR CONTRIBUTIONS}

$\mathrm{AD}, \mathrm{BL}, \mathrm{MC}, \mathrm{AF}$, and $\mathrm{NA}$ substantially contributed to the conception of the work, the acquisition, analysis and interpretation of data and drafting and critically revising the 
work. $\mathrm{FB}, \mathrm{BD}, \mathrm{CD}$, and JS substantially contributed to drafting and critically revising the work. All authors have final approval of the version to be published and agree to be accountable for all aspects of the work.

\section{REFERENCES}

Badali, H., Chander, J., Gulati, N., Attri, A., Chopra, R., Najafzadeh, M. J., et al. (2010a). Subcutaneous phaeohyphomycotic cyst caused by Pyrenochaeta romeroi. Med. Mycol. 48, 763-768. doi: 10.3109/13693780903440383

Badali, H., Najafzadeh, M. J., van Esbroeck, M., van den Enden, E., Tarazooie, B., Meis, J. F. G. M., et al. (2010b). The clinical spectrum of Exophiala jeanselmei, with a case report and in vitro antifungal susceptibility of the species. Med. Mycol. 48, 318-327. doi: 10.1080/13693780903148353

Ben-Ami, R., Lewis, R. E., Raad, I. I., and Kontoyiannis, D. P. (2009). Phaeohyphomycosis in a tertiary care cancer center. Clin. Infect. Dis. 48, 1033-1041. doi: 10.1086/597400

Borelli, D. (1979). Opportunistic fungi as producers of gray colonies and mycetomata. Dermatologica 159, 168-174. doi: 10.1159/000250685

Chowdhary, A., Meis, J. F., Guarro, J., de Hoog, G. S., Kathuria, S., Arendrup, M. C., et al. (2014). ESCMID and ECMM joint clinical guidelines for the diagnosis and management of systemic phaeohyphomycosis: diseases caused by black fungi. Clin. Microbiol. Infect. 20(Suppl. 3), 47-75. doi: 10.1111/1469-0691.12515

de Gruyter, J., Aveskamp, M. M., Woudenberg, J. H. C., Verkley, G. J. M., Groenewald, J. Z., and Crous, P. W. (2009). Molecular phylogeny of Phoma and allied anamorph genera: towards a reclassification of the Phoma complex. Mycol. Res. 113, 508-519. doi: 10.1016/j.mycres.2009.01.002

Ferrer, C., Pérez-Santonja, J. J., Rodríguez, A. E., Colom, M. F., Gené, J., Alio, J. L., et al. (2009). New pyrenochaeta species causing keratitis. J. Clin. Microbiol. 47, 1596-1598. doi: 10.1128/JCM.01912-08

Girard, C., Dereure, O., Rispail, P., Durand, L., and Guilhou, J. (2004). Subcutaneous phaeohyphomycosis due to Pyrenochaeta romeroi in a patient with leprosy. Acta Derm. Venereol. 84, 154-155. doi: 10.1080/00015550310006824

Khan, Z., Ahmad, S., Kapila, K., Ramaswamy, N. V, Alath, P., Joseph, L., et al. (2011). Pyrenochaeta romeroi: a causative agent of phaeohyphomycotic cyst. J. Med. Microbiol. 60, 842-846. doi: 10.1099/jmm.0.029520-0

Oliveira, W. R., Borsato, M. F., Dabronzo, M. L., Festa Neto, C., Rocha, L. A., and Nunes, R. S. (2016). Phaeohyphomycosis in renal transplantation: report of two cases. An. Bras. Dermatol. 91, 89-92. doi: 10.1590/abd1806-4841.20163954

Rinaldi, M. G. (1996). Phaeohyphomycosis. Dermatol. Clin. 14, 147-153. doi: 10.1016/S0733-8635(05)70335-1

\section{ACKNOWLEDGMENT}

The authors would like to thank Elodie Choisy for her help during this work.

Ronan, S. G., Uzoaru, I., Nadimpalli, V., Guitart, J., and Manaligod, J. R. (1993). Primary cutaneous phaeohyphomycosis: report of seven cases. J. Cutan. Pathol. 20, 223-228. doi: 10.1111/j.1600-0560.1993.tb00647.x

Santos, D. W. C. L., Padovan, A. C. B., Melo, A. S. A., Gonçalves, S. S., Azevedo, V. R., Ogawa, M. M., et al. (2013). Molecular identification of melanised non-sporulating moulds: a useful tool for studying the epidemiology of phaeohyphomycosis. Mycopathologia 175, 445-454. doi: 10.1007/s11046012-9608-x

Sharma, S., Capoor, M. R., Singh, M., Kiran, D., and Mandal, A. K. (2016). Subcutaneous phaeohyphomycosis caused by Pyrenochaeta romeroi in a rheumatoid arthritis patient: a case report with review of the literature. Mycopathologia doi: 10.1007/s11046-016-0022-27 [Epub ahead of print].

Thammayya, A., Sanyal, M., and Basu, N. (1979). Pyrenochaeta romeroi causing mycetoma pedis in India. J. Indian Med. Assoc. 73, 66-67.

Vásquez-del-Mercado, E., Lammoglia, L., and Arenas, R. (2013). Subcutaneous phaeohyphomycosis due to Curvularia lunata in a renal transplant patient. Rev. Iberoam. Micol. 30, 116-118. doi: 10.1016/j.riam.2012. 10.004

Verkley, G. J. M., Gené, J., Guarro, J., Pérez-Santonja, J. J., Rodríguez, A. E., Colom, M. F., et al. (2010). Pyrenochaeta keratinophila sp. nov., isolated from an ocular infection in Spain. Rev. Iberoam. Micol. 27, 22-24. doi: 10.1016/j.riam.2009.09.001

Yadav, S., Agarwal, R., Singh, S., and Goel, S. (2015). Pyrenochaeta romeroi causing subcutaneous phaeohyphomycotic cyst in a diabetic female. Med. Mycol. Case Rep. 8, 47-49. doi: 10.1016/j.mmcr.2015.04.001

Conflict of Interest Statement: The authors declare that the research was conducted in the absence of any commercial or financial relationships that could be construed as a potential conflict of interest.

Copyright (c) 2016 Dinh, Levy, Bouchand, Davido, Duran, Cristi, Felter, Salomon and Ait Ammar. This is an open-access article distributed under the terms of the Creative Commons Attribution License (CC BY). The use, distribution or reproduction in other forums is permitted, provided the original author(s) or licensor are credited and that the original publication in this journal is cited, in accordance with accepted academic practice. No use, distribution or reproduction is permitted which does not comply with these terms. 